Moura, O., Simões, M. R., \& Pereira, M. (2015). Working memory in Portuguese children with developmental dyslexia. Applied Neuropsychology: Child, 4(4), 237-248.

doi:10.1080/21622965.2014.885389

\title{
Working Memory in Portuguese Children with Developmental Dyslexia
}

\begin{abstract}
A Portuguese sample of 50 children with developmental dyslexia and 50 typical readers who were matched for age ( 8 to 12 years old) were tested on measures of working memory. Relative to the typical readers, the children with developmental dyslexia performed significantly lower on phonological loop and central executive tasks; however, they exhibited no impairments on visuospatial sketchpad tasks. After controlling for the influence of the phonological loop, the group differences in central executive were no longer significant. The results of a receiver operating characteristics curve analysis and a binary logistic regression analysis suggested that the phonological loop and central executive tasks (but not the visuospatial sketchpad tasks) were relevant variables for identifying children with developmental dyslexia. Hierarchical linear regression analyses showed that the phonological loop and central executive (Backward Digit Span only) tasks were significant predictors of reading and spelling abilities.
\end{abstract}

Keywords: working memory, short-term memory, developmental dyslexia, reading, spelling 


\section{Introduction}

Working memory (WM) refers to a limited-capacity memory system that is involved in the temporary storage and processing of verbal and visuospatial information. WM is distinguished from other forms of memory because it reflects both processing and storage capacity (Baddeley, 2000, 2003). Although various models of WM have been developed (e.g., Cowan, 1999; Engle, Kane, \& Tuholski, 1999), the framework of WM proposed by Baddeley and Hitch (1974) is the most widely used in studies of children with learning disabilities or other neurodevelopmental disorders. This WM model is conceptualized as a multi-component system comprising a central executive (CE) and two slave systems: the phonological loop (PL) and the visuospatial sketchpad (VSSP). The two slave systems are often referred to as short-term memory (STM), whereas the CE is also referred to as WM (e.g., Just \& Carpenter, 1992; Swanson, Zheng, \& Jerman, 2009).

The PL is a peripheral slave system specialized for the temporary storage of verbal information. This system comprises a limited phonological store, which can hold memory traces for a few seconds, and an articulatory rehearsal process, which prevents the decay of material stored in the phonological store by successively refreshing memory traces (Baddeley, 2003, 2012). Tasks that measure the PL typically assess the subject's capacity to recall a sequence of verbal items (e.g., digits, letters and words) in the order in which they were presented. The VSSP is a limited-capacity peripheral slave system specialized for the temporary storage of visual and spatial material. Although spatial and visual information was initially considered to be processed by a single VSSP system, subsequent neuropsychological studies have indicated the need to distinguish between visual and spatial STM (Della Sala, Gray, Baddeley, Allamano, \& Wilson, 1999; Pickering, Gathercole, Hall, \& Lloyd, 2001). Logie and colleagues (1995; Logie \& Pearson, 1997) suggested a fractionation of the sketchpad into two subcomponents: a visual cache (temporary visual storage) and an inner scribe (retrieval and a rehearsal 
mechanisms; analogous to the articulatory rehearsal of the PL). Dynamic (e.g., Corsi Block Test) and static (e.g., Visual Patterns Test) span tasks are typically used to measure spatial and visual memory, respectively. The $\mathrm{CE}$ is a supervisory system that is responsible for controlling and manipulating information stored in the two slave systems, and it is often linked to the functioning of the frontal lobes (Baddeley, 1996, 2003). Baddeley (1996) described four functions of the CE: (i) the coordination of multiple tasks; (ii) the capacity to switch between tasks or retrieval strategies; (iii) the capacity to selectively attend to one stimulus while inhibiting others; and (iv) the capacity to retain and manipulate information in long-term memory. Thus, CE tasks (e.g., backward digit span tasks) place greater demands on executive functioning because they require the simultaneous storage and processing of information. Jerman, Reynolds, and Swanson (2012) noted the existence of a considerable overlap between the processes involved in $\mathrm{CE}$ and executive functions.

Because a number of phenomena were not addressed by the original three-component model of WM, Baddeley (2000) proposed the inclusion of a fourth component, the episodic buffer, which is controlled by the $\mathrm{CE}$ and is responsible for integrating information from a variety of sources. The episodic buffer, a limited-capacity system that provides the temporary storage of information held in a multimodal code, is capable of binding information from both the slave systems and long-term memory into a unitary episodic representation (Baddeley, 2012; Baddeley, Allen, \& Hitch, 2011). More recently, in an effort to account for the impact of emotion on cognition, Baddeley (2013; Baddeley, Banse, Huang, \& Page, 2012) proposed the existence of a hedonic detection system coupled to WM.

\section{Working Memory Impairments in Developmental Dyslexia}

Impairments in WM have been described as one of the major defining characteristics of developmental dyslexia (DD). For years, neurocognitive researchers have observed that children 
with DD performed extremely poorly on subtests corresponding to the current Working Memory Index of the Wechsler Intelligence Scale for Children (WISC) - Fourth Edition (ClercqQuaegebeur et al., 2010; Helland \& Asbjornsen, 2004; Moura, Simões, \& Pereira, 2013). Studies employing more specific measures have also reported that children with DD exhibit strong evidence of WM impairments, particularly in the PL and CE components (Jeffries \& Everatt, 2004; Menghini, Finzi, Carlesimo, \& Vicari, 2011; Schuchardt, Maehler, \& Hasselhorn, 2008).

Almost all studies investigating PL capacity have documented reductions in verbal span in children with DD (Kibby \& Cohen, 2008; Menghini et al., 2011; Swanson et al., 2009; Willcutt, Pennington, Olson, Chhabildas, \& Hulslander, 2005). Nonetheless, the literature has been discordant concerning which PL subcomponents are compromised. Some researchers have observed that the deficit appeared to be specific to the store mechanism (a reduced phonological similarity effect; i.e., rhyming items are more difficult to remember than non-rhyming items), while the subvocal rehearsal mechanism remained intact. However, others have found that children with DD exhibited less-efficient rehearsal processes (a reduced word length effect; i.e., short words are easier to remember than sequences of long words) or that phonological similarity and word length effects did not differ between children with DD and typical readers (TR) (Kibby, 2009; Pickering, 2004; Steinbrink \& Klatte, 2008). Moreover, some researchers have found an association between PL and articulatory/speech rate (i.e., the number of verbal items repeated per second), suggesting that children with DD experience PL impairments due to their slow articulation rates, which cause the PL to function less efficiently (Kibby, 2009; McDougall \& Donohoe, 2002). The PL also plays an important role in the development of reading skills. A large number of studies have demonstrated that the PL predicts reading decoding (Hulme, Goetz, Gooch, Adams, \& Snowling, 2007; Kibby, 2009; Perez, Majerus, \& Poncelet, 2012) and reading comprehension (Goff, Pratt, \& Ong, 2005; Swanson \& Ashbaker, 
2000). Other researchers have found that the PL did not uniquely predict reading after controlling for phonological awareness and naming speed tasks (Parrila, Kirby, \& McQuarrie, 2004).

VSSP capacity has been associated with visuospatial reasoning (Kane et al., 2004), spatial orientation (Baddeley, 2002) and arithmetic abilities (Holmes, Adams, \& Hamilton, 2008; Sarver et al., 2012), and it appears to be diminished in some children with learning disabilities, such as dyscalculia (Ashkenazi, Rosenberg-Lee, Metcalfe, Swigart, \& Menon, 2013; Schuchardt et al., 2008). Research on the relationship between DD and VSSP deficits has yielded mixed results. Although most studies have not found VSSP deficits in individuals with DD (Bacon, Parmentier, \& Barr, 2013; Jeffries \& Everatt, 2004; Kibby \& Cohen, 2008; Schuchardt et al., 2008), others have suggested the presence of significant differences, with individuals with DD performing more poorly than TR (Menghini et al., 2011; Smith-Spark \& Fisk, 2007). When visuospatial STM tasks involve CE demands, children with DD tend to exhibit more difficulties. For instance, Bacon et al. (2013) demonstrated that children with DD exhibited no deficits in the forward recall task of the Corsi Block Test but revealed significant impairments in the backward recall task. In addition, studies comparing the VSSP capacities of children with DD and those with other neurodevelopment disorders have found that children with DD performed better than children with comorbid dyslexia/dyscalculia (Landerl, Fussenegger, Moll, \& Willburger, 2009) or other learning difficulties (Jeffries \& Everatt, 2004) but achieved scores similar to those of children with attention deficit hyperactivity disorder (ADHD) (Willcutt et al., 2005). Among the limited studies that have explored the predictive power of VSSP tasks for reading performance, some have found that VSSP predicts long-term reading achievement (Sarver et al., 2012), reading fluency (Nevo \& Breznitz, 2011) and reading comprehension (Goff et al., 2005). However, others found no predictive value of VSSP tasks for reading decoding or reading comprehension (Gathercole, Alloway, Willis, \& Adams, 2006; Nevo \& Breznitz, 2011). 
As described above, the $\mathrm{CE}$ is responsible for controlling and processing information stored in STM, which involves the activation of various cognitive processes. Strong empirical evidence supports the presence of significant CE impairments in children with DD (Savage, Lavers, \& Pillay, 2007; Swanson et al., 2009). These CE deficits may occur in the presence or absence of significant deficits in the PL or VSSP (Jeffries \& Everatt, 2004; Smith-Spark \& Fisk, 2007; Swanson, 2012; Swanson \& Jerman, 2007), suggesting that the memory deficits associated with DD go beyond the temporary storage of information; information processing is also compromised. However, controlling the influence of PL on CE performance has produced contradictory results. For instance, de Jong (1998) and Smith-Spark and Fisk (2007) found significant differences in the mean scores of individuals with DD and TR on CE tasks, even after PL tasks were controlled through covariance. In contrast, Schuchardt et al. (2008) observed that group differences in CE performance were no longer significant when PL tasks were taken into account. Furthermore, the presence of intact CE functioning in children with DD has also been reported (Kibby \& Cohen, 2008; Landerl et al., 2009; van der Sluis, van der Leij, \& de Jong, 2005). Numerous studies have found that CE predicted variance in reading decoding (Gathercole et al., 2006; Jerman et al., 2012; Nevo \& Breznitz, 2011; Swanson \& Ashbaker, 2000), reading comprehension (Sesma, Mahone, Levine, Eason, \& Cutting, 2009; Swanson \& Jerman, 2007), reading fluency (Berninger et al., 2006; Nevo \& Breznitz, 2011; Swanson \& Jerman, 2007), and mathematical ability (Andersson, 2008; Jerman et al., 2012). Conversely, some studies have not found a predictive effect of CE on reading accuracy and/or reading comprehension (Berninger et al., 2006; Sesma et al., 2009).

The current study was undertaken to assess the extent to which WM is impaired in Portuguese children with DD. The European Portuguese language is considered an orthography of intermediate depth; more transparent than English and French, but less regular than German, Spanish, Italian or Finnish (Seymour, Aro, \& Erskine, 2003; Sucena, Castro, \& Seymour, 2009). 
Seymour et al. (2003) examined the beginning of reading acquisition in 13 European orthographies and found that children become fluent and accurate before the end of first grade. The exceptions to this reading development pattern were English, French, Danish and Portuguese (the Portuguese and French orthographic code learning trajectories were quite similar). Based on the existing literature (the large body of research about WM deficits in DD has been conducted on English-speaking samples), three predictions were made. First, it was expected that Portuguese children with DD who were native speakers of an orthography of intermediate depth would also show significant impairments in PL and CE but exhibit an intact VSSP. Second, it was expected that the PL and CE (but not the VSSP) would be accurate measures for discriminating between subjects (children with DD and TR). Third, as observed in other languages spanning a large range of orthographic complexity, it was hypothesized that only the PL and CE would be significant predictors of reading and spelling in the Portuguese orthography. Few studies have explored the accuracy of WM for discriminating between typical readers and children with DD, and few have analyzed the predictive power of WM for spelling. Furthermore, no published studies have analyzed WM performance among Portuguese children with DD.

\section{Method}

\section{Participants}

The participants were 100 Portuguese children between the ages of 8 and 12 years $(M=$ 9.81; $S D=1.34)$ in the $3^{\text {rd }}$ to $6^{\text {th }}$ school grades. The DD group $(N=50)$ included $74 \%$ male and $26 \%$ female subjects, with a mean age of 9.80 years $(S D=1.38)$. Among the children with DD, $26 \%$ had experienced school retention, $36 \%$ were included in special education system, $94 \%$ had attended kindergarten, and 30\% had relatives with reading difficulties. The TR group $(N=50)$ included $64 \%$ male and $36 \%$ female subjects, with a mean age of 9.82 years $(S D=1.32)$. All the 
TR had attended kindergarten, only $2 \%$ had experienced school retention, and $4 \%$ had relatives with reading difficulties. The children in the DD and TR groups were matched for age $\chi^{2}(4)=$ $0.487, p=.975$, yielding non-significant differences in gender $\chi^{2}(1)=1.169, p=.387$ and grade $\chi^{2}(3)=1.776, p=.620$.

Criteria for Inclusion. For both groups, only children who met the following criteria were included: (i) Wechsler Intelligence Scale for Children - Third Edition (WISC-III) Full Scale IQ (FSIQ) $\geq 90$; (ii) native speakers of European Portuguese; (iii) at least two years of school attendance; (iv) the absence of visual, auditory or motor handicaps; and (v) the absence of language impairments, emotional disturbances, dyscalculia, disruptive behavior disorders (ADHD, oppositional defiant disorder or conduct disorder), neurological impairments or other psychiatric disorders. Children with special educational needs were also excluded from the TR group.

In the DD group, only children who had previously been diagnosed with DD by a psychologist, child psychiatrist, developmental pediatrician, or child neurologist and had received a score lower than or equal to the $15^{\text {th }}$ percentile on a reading fluency and accuracy measure ("O Rei"; Carvalho \& Pereira, 2009) administered during the testing session were included. These cutoff scores (WISC-III FSIQ $\geq 90$ and reading fluency and accuracy measures both $\leq 15^{\text {th }}$ percentile) were similar to (and in some cases stricter than) the inclusion criteria used in previous studies assessing WM deficits in individuals with DD (e.g., Schuchardt et al., 2008; Swanson, 2011, 2012; Tiffin-Richards, Hasselhorn, Woerner, Rothenberger, \& Banaschewski, 2008).

\section{Measures and Procedures}

Intellectual Ability. The Portuguese version of the WISC-III (Wechsler, 2003), which was normed on a representative sample of 1354 children (aged 6 to 16 years), was administered 
to measure general intellectual ability. The factor structure of the Portuguese version of WISCIII, analyzed through an exploratory and confirmatory factor analysis, yielded adequate psychometric properties for a two-factor model (Verbal IQ and Performance IQ) and for a threefactor model (Verbal Comprehension, Perceptual Organization and Processing Speed). The reliability of the WISC-III FSIQ was .89 (linear combinations), with a test-retest correlation coefficient of .92 (Wechsler, 2003). The subjects' FSIQ scores $(M=100 ; S D=15)$ were analyzed and used as a covariate in the inferential analysis.

Phonological Loop. The Forward task from the Digit Span ${ }^{1}$ subtest of the WISC-III (Forward DS) and the Verbal Learning Test from the Coimbra Neuropsychological Assessment Battery $^{2}$ (BANC; Simões et al., in press) were selected to assess verbal STM. The Forward DS required that the child correctly recall a series of two to nine digits in the order in which they were presented. One point per trial was given for a correct repetition. In the Verbal Learning Test, a list of 15 unrelated words was read to the child four consecutive times. Following each trial, the child was asked to recall as many words as possible. A new list with 15 words was then

\footnotetext{
${ }^{1}$ The reliability of the Digit Span subtest was .80 (split-half), with a test-retest correlation coefficient of .72 (Wechsler, 2003).
}

\footnotetext{
${ }^{2}$ The BANC is a comprehensive assessment instrument tapping different functions of children's neuropsychological development, which included 16 tests organized in six main domains: Memory (Verbal Learning Test, Narrative Memory, Memory of Faces, Rey Complex Figure Test, and Corsi Block Test); Language (Phonological Awareness, Instruction Comprehension, and Rapid Naming); Attention and Executive Functions (Cancellation, Trail, Semantic Verbal Fluency, Phonemic Verbal Fluency, and Tower); Motricity; Laterality; and Orientation. The BANC (Simões et al., in press) was normed on a representative and stratified sample of 1104 Portuguese children (aged 5 to 15 years) and revealed adequate psychometric properties [e.g., confirmatory factor analysis yielded an adequate model fit with Comparative Fit Index $(\mathrm{CFI})=.965$ and Root Mean Square Error of Approximation $(\mathrm{RMSEA})=.044$ for children aged 7 to 9 years; and CFI $=.966$ and $\mathrm{RMSEA}=.046$ for children aged 10 to 15 years].
} 
presented and recalled once (interference recall). Then, the child was asked to recall the first word list immediately (immediate recall) and after a 20- to 30-minute delay (delayed recall). Finally, a list of 45 words (15 from the first list, 15 from the interference list, and 15 new) was presented, and the child was asked to identify the 15 first-list words (recognition). Because the purpose of the Verbal Learning Test was to measure PL, only the first trial score (i.e., the first time that the child was asked to recall the 15 words) was considered in the subsequent analyses. These tasks are conventional measures used to assess verbal STM (Bora et al., 2008; Jeffries \& Everatt, 2004; Kramer, Knee, \& Delis, 2000; Schuchardt et al., 2008).

Visuospatial Sketchpad. The Corsi Block Test and the Rey Complex Figure Test (RCFT) were administered to measure VSSP. The Corsi Block Test consists of nine blocks nailed onto a board at random positions. The child was asked to reproduce the sequence (from two to nine blocks) by touching the blocks in the same order as the experimenter. The task ended when the child failed to reproduce both trials at any particular span length. One point per trial was given for a correct reproduction. In the RCFT, the child was instructed to copy the complex figure as accurately as possible and to then reproduce it from memory 3 minutes later (immediate recall) and 20 to 30 minutes later (delayed recall). The Meyers and Meyers (1995) scoring system was used (each of the 18 elements was scored with $2,1,0.5$ or 0 points according to its presence, accuracy and location). Because the purpose of the RCFT was to measure visuospatial STM, only the immediate recall score was considered. These two tasks are widely used to assess visuospatial STM (Brunswick, Martin, \& Marzano, 2010; Maehler \& Schuchardt, 2011; SmithSpark \& Fisk, 2007; Wisniewski, Wendling, Manning, \& Steinhoff, 2012).

Central Executive. The Backward task from the Digit Span subtest of the WISC-III (Backward DS) and the Trail from the BANC were chosen to assess the CE component of WM. Backward DS is extensively used as a measure of CE because it assesses the ability to briefly maintain and manipulate information in WM (Jeffries \& Everatt, 2004; Schuchardt et al., 2008; 
Tiffin-Richards et al., 2008). This task required that the child correctly recall a series of two to eight digits in the reverse order. One point per trial was given for correct recall. The Trail (Part A and B), which is similar to the popular Trail Making Test, was chosen because it is another frequently used measure of CE functioning (Andersson, 2008; Baddeley, 1996; McLean \& Hitch, 1999). In Trail-A, 25 encircled numbers were randomly distributed on a sheet of paper. The child had to draw a line connecting the numbers sequentially from 1 to 25 as rapidly and accurately as possible. In Trail-B, the child has to draw a line connecting 25 circles with numbers or letters, randomly distributed on a sheet of paper. The child had to draw a line connecting the circles, alternating between numbers and letters (e.g., 1, A, 2, B, etc.), as rapidly and accurately as possible. Thus, Trail-B required that the child focus on both alphabetical and numerical series while simultaneously remembering whether a letter or number should occur next in the series. The raw scores of Trail-A and Trail-B represented the amount of time (in seconds) required to complete the tasks. As suggested by some authors (Andersson, 2008; Drane, Yuspeh, Huthwaite, \& Klingler, 2002), to obtain a "purer" measure of shifting, the difference between the Trail-B and Trail-A scores (Trail B-A) was used in the subsequent analyses.

Reading and Spelling Measures. Four measures were used to assess reading and spelling abilities: text reading accuracy, text reading fluency, word reading accuracy, and word spelling accuracy. The "O Rei” ("The King"; Carvalho \& Pereira, 2009), an individually administered reading test for children that involves a Portuguese traditional tale, was chosen to measure text reading accuracy (the percentage of correctly read words) and text reading fluency (the number of words read in one minute). To assess word reading and word spelling accuracy, we used the Oral Reading subtest from the Portuguese version (Festas, Martins, \& Leitão, 2007) of the Psycholinguistic Assessment of Language (PAL; Caplan, 1992). This subtest comprises 146 words (48 regular, 47 irregular and 51 pseudowords). Based on previous studies of typically 
developing children, we selected 40 words: 16 regular ( 8 high-frequency and 8 low-frequency words; e.g., sardinha and delonga), 16 irregular (8 high-frequency and 8 low-frequency words; e.g., brinquedo and exotismo) and 8 pseudowords (e.g., lempo and glepal). This subtest was used in both the reading and spelling tasks, which were separated by an interval of 10 to 15 days.

The administration of these tests was included as part of a broad neuropsychological research that also comprises other measures (e.g., phonological awareness, naming speed, and attention). Each child completed two individual sessions (separated by an interval of 10 to 15 days), lasting approximately 90 minutes per session, in a clinic or school setting during a weekday. All measures were administered by the first author in a fixed order. No incentives were offered in exchange of participation.

\section{Statistical Analyses}

The statistical analyses were performed using IBM SPSS Statistics 19. Group differences were analyzed using multivariate analyses of variance (MANOVA) and covariance (MANCOVA) for each WM component. If the multivariate analysis indicated a significant overall difference $(p<.05)$, then a univariate test was applied to determine which dependent variables were responsible for the multivariate difference. In specific cases, an independentsamples t-test was also used. Partial eta-squared $\left(\eta^{2}\right.$ p) or Cohen's $d$ was calculated to determine the effect size of the difference between groups.

A receiver operating characteristics (ROC) curve and a binary logistic regression analysis were performed to assess the accuracy of the WM tasks to correctly discriminate between children with DD and TR. A ROC curve analysis systematically sweeps across all possible truepositive (sensitivity) and false-positive (1-specificity) values of a diagnostic test and calculates the area under the curve (AUC), which provides an accuracy index of the test (Fawcett, 2006). 
An AUC value of .5 to .7 indicates low test accuracy; .7 to .9 indicates moderate accuracy; and .9 to 1.0 indicates high accuracy (Swets, 1988). For the binary logistic regression analysis, the fit of the model (Hosmer-Lemeshow test, Cox and Snell $R^{2}$, and Nagelkerke $R^{2}$ ) and the statistical tests of individual predictors were analyzed (regression coefficient, Wald's $\chi^{2}$, and odds ratio).

To determine the predictive value of WM for reading and spelling abilities, hierarchical linear regression analyses were also conducted. The total variance $\left(R^{2}\right)$ of the regression model, the t-test $(t)$, the squared part correlation $\left(p r^{2}\right)$, the standard error $(S E)$, and the unstandardized (B) and standardized ( $\beta$ ) regression coefficients for each independent variable were calculated.

\section{Results}

\section{Group Differences}

The WISC-III FSIQ scores differed significantly, $t(98)=4.721, p<.001, d=0.95$, between the TR $(M=108.24 \pm 11.64)$ and the children with DD $(M=98.53 \pm 8.55)$. Therefore, group differences were tested using MANOVA and MANCOVA, with WISC-III FSIQ as a covariate.

For the PL, a MANOVA was performed with Forward DS and Verbal Learning Test (first trial score) as dependent variables and reading group (TR and children with DD) as fixed factor. Reading group had a significant effect, $F(2,97)=12.028, p<.001$, Wilks' $\Lambda=.800, \eta^{2}{ }_{p}=.200$. The univariate analysis revealed significant effects in both PL tasks, with the TR (Forward DS = $7.36 \pm 1.45$, Verbal Learning Test $=6.58 \pm 1.75$ ) outperforming the children with DD (Forward $\mathrm{DS}=6.20 \pm 1.13$, Verbal Learning Test $=5.59 \pm 1.60$ ). Significant differences for PL remained when WISC-III FSIQ was used as a covariate, $F(2,96)=7.652, p=.001$, Wilks' $\Lambda=.861, \eta^{2}$ p .139 (see Table 1). 
For the VSSP, the scores on the Corsi Block Test and RCFT (immediate recall) were entered into a MANOVA, with reading group as a fixed factor. The multivariate main effect of reading group was not significant, $F(2,97)=1.346, p=.265$, Wilks' $\Lambda=.973, \eta^{2}{ }_{\mathrm{p}}=.027$ (Corsi Block Test: $\mathrm{TR}=7.74 \pm 1.93$, children with $\mathrm{DD}=7.18 \pm 1.53$; RCFT: $\mathrm{TR}=15.86 \pm 5.77$; children with $\mathrm{DD}=15.25 \pm 5.67)$. The result remained non-significant when a MANCOVA controlling for differences in intelligence was performed, $F(2,96)=0.558, p=.574$, Wilks' $\Lambda=$ $.988, \eta_{\mathrm{p}}^{2}=.012($ see Table 1$)$.

The scores on the two tasks tapping CE functioning were entered into a MANOVA, and the multivariate main effect of reading group proved to be significant, $F(2,97)=11.243, p<$ .001 , Wilks' $\Lambda=.810, \eta_{\mathrm{p}}^{2}=.190$. At the univariate level, significant group differences were observed for Backward DS and Trail B-A: compared with the TR, the children with DD recalled fewer digits in the backward condition $(\mathrm{TR}=4.56 \pm 1.34$, children with $\mathrm{DD}=3.63 \pm 0.97)$ and required more time to complete the Trail $\mathrm{B}-\mathrm{A}(\mathrm{TR}=53.98 \pm 27.71$, children with $\mathrm{DD}=77.00 \pm$ 36.11). After controlling for differences in the WISC-III FSIQ, the multivariate main effect of reading group remained significant, $F(2,96)=5.852, p=.004$, Wilks' $\Lambda=.890, \eta^{2}{ }_{p}=.110($ see Table 1).

(Table 1 about here)

Because $\mathrm{CE}$ tasks require both the temporary storage and processing of information, it has been hypothesized that differences in temporary storage systems might underlie group differences in CE. To examine this hypothesis, a MANCOVA was performed with the two CE tasks as dependent variables, reading group as a fixed factor and the two PL tasks as covariates. This type of analysis was not performed for VSSP because a previous inferential analysis did not show significant differences. After controlling for PL tasks, no significant group differences 
in CE remained, $F(2,95)=2.856, p=.062$, Wilks' $\Lambda=.943, \eta^{2}{ }_{p}=.057$ (although the $p$-value was closer to statistical significance), suggesting that the group differences in CE could be accounted for by differences in PL.

\section{Diagnostic Accuracy}

The results of previous inferential analyses indicated significant group differences in PL and CE; however, this does not imply that WM tasks can correctly discriminate between children with DD and TR. Therefore, ROC curve and a binary logistic regression analyses were performed.

The results of the ROC curve analysis revealed that only the PL and CE tasks were significant variables for discriminating between subjects. The more accurately a task discriminates between groups, the higher is its AUC value. The AUC values of the Forward DS, Backward DS, and Trail B-A tasks revealed moderate levels of accuracy, indicating that a randomly selected child with DD will receive a lower score than a randomly selected TR approximately $73.7 \%, 70.4 \%$ and $70.7 \%$ of the time, respectively (see Table 2 ).

An individual binary logistic regression analysis was performed for each WM component. For the PL, the logistic regression model yielded a Hosmer-Lemeshow $\chi^{2}(8)=7.372, p=.497$, suggesting that the model fit the data well. The Cox and Snell $R^{2}=.206$, and the Nagelkerke $R^{2}$ $=.274$. The PL correctly classified $68.7 \%$ of the children (sensitivity $=73.5 \%$ and specificity $=$ $64 \%$ ). Only the Forward DS task was a significant predictor, with an odds ratio of 0.492 (i.e., with each one-point increase in the Forward DS score, the odds of being in the DD group decreased from 1 to 0.492$)$. For the VSSP, a Hosmer-Lemeshow $\chi^{2}(8)=1.854, p=.985$; Cox and Snell $R^{2}=.027$; and Nagelkerke $R^{2}=.036$ were obtained. This logistic regression model correctly classified $55 \%$ of the children (sensitivity $=62 \%$ and specificity $=48 \%$ ). Neither the Corsi Block Test nor the RCFT (immediate recall) was a significant predictor. For the CE, the 
goodness-of-fit test yielded a Hosmer-Lemeshow $\chi^{2}(8)=7.301, p=.504$, with a Cox and Snell $R^{2}=.200$ and a Nagelkerke $R^{2}=.267$. This model correctly classified $65.6 \%$ of the children $($ sensitivity $=57.1 \%$ and specificity $=74 \%)$, and both CE tasks were significant predictors. Each one-point increase in the Backward DS score decreased the odds of being in the DD group by $48.8 \%$, whereas every one-second increase in the Trail B-A score increased the odds of being in the DD group by $1.9 \%$ (see Table 3 ).

(Table 2 about here)

(Table 3 about here)

\section{Predictive Effect of Working Memory on Reading and Spelling Abilities}

Hierarchical linear regression analyses were performed to determine whether the WM tasks were predictive variables for reading and spelling abilities. Four regression models were performed, one for each dependent variable (text reading accuracy, text reading fluency, word reading accuracy, and word spelling accuracy). The predictive variables were entered in the following order: PL tasks were entered into the first block, VSSP tasks were entered next, and CE tasks were entered last. The $B, S E, \beta$ and $t$ values shown in Table 4 are relative to the last block. The $p r^{2}$ value represents the unique variance of each predictor after the overlapping linear effects of all the other predictive variables were statistically removed.

For text reading accuracy, the regression model was statistically significant, $F(6,92)=$ 5.364, $p<.001$, and explained $25.9 \%$ of the total variance. After controlling for the PL tasks, the VSSP tasks explained only $1.1 \%$ of the variance. The CE tasks explained an additional $7.6 \%$ of the variance. Only the Verbal Learning Test (5.1\% of unique variance) and the Backward DS ( $7.3 \%$ of unique variance) were significant predictors. 
For text reading fluency, the regression model was statistically significant, $F(6,92)=$ 15.447, $p<.001$, and explained $50.2 \%$ of the total variance. After controlling for the PL tasks, the VSSP accounted for $1.2 \%$ of the variance, whereas the CE tasks uniquely accounted for $15.2 \%$ of the variance. The Forward DS, Verbal Learning Test and Backward DS were significant predictors, with unique variances of $2.3 \%, 5.9 \%$ and $15.1 \%$, respectively.

Regressing the word reading accuracy scores on measures of WM yielded a significant model, $F(6,92)=6.383, p<.001$, which explained $29.4 \%$ of the total variance. After controlling for the PL and VSSP tasks, the CE tasks uniquely accounted for $5.7 \%$ of the variance. Again, only the Verbal Learning Test (4.8\% of unique variance) and the Backward DS (5.5\% of unique variance) were significant predictors.

Finally, regressing the word spelling accuracy scores on the WM measures also yielded a significant model, $F(6,92)=8.843, p<.001$, which explained $36.6 \%$ of the total variance. After controlling for the PL, the VSSP tasks explained only $1.8 \%$ of the variance, whereas the CE tasks uniquely accounted for $4.5 \%$ of the variance. The Forward DS, Verbal Learning Test and Backward DS were significant predictors, with unique variances of $3.8 \%, 5.3 \%$ and $4 \%$, respectively (see Table 4).

(Table 4 about here)

\section{Discussion}

WM deficits have been widely studied and identified as one of the major defining characteristics of DD. Whereas the deficits in PL and CE tasks exhibited by children with DD have been reported extensively (Schuchardt et al., 2008; Smith-Spark \& Fisk, 2007; Swanson et al., 2009), the findings regarding VSSP have been inconsistent (Bacon et al., 2013; Kibby \& Cohen, 2008; Menghini et al., 2011). 
Thus, the first purpose of the present study was to investigate the specificity of WM deficits in Portuguese children with DD. Consistent with the published literature and our initial hypothesis, the children with DD performed worse than the TR on PL tasks. This finding, which applied to tasks involving both word list recall and digit span tests, suggests that children with DD experience difficulty when required to perform memory tasks involving verbal material. Similarly, de Jong (1998), and Maehler and Schuchardt (2011) found that children with DD performed significantly lower than typically developing children on word span and forward digit span tasks. The WM deficits exhibited by the children with DD were not confined to the PL, CE impairments were also observed. The TR outperformed the children with DD on both CE tasks, indicating that both the storage and processing of information were compromised in the children with DD. These results are consistent with the findings of a recent meta-analysis (Swanson et al., 2009) that revealed particular deficits in verbal STM and CE measures among children with DD. Consistent with other studies (Jeffries \& Everatt, 2004; Schuchardt et al., 2008), we did not find significant differences in VSSP between the groups, suggesting that the WM deficits associated with DD are more specific to the PL and CE components. All the group differences in the WM components remained after general intellectual ability was controlled for, suggesting that the observed variations in PL, VSSP and CE were unrelated to differences in intelligence. Swanson et al. (2009) reported a non-significant moderating effect of intelligence on the magnitude of the effect sizes of STM and CE measures between children with and without DD. Contrary to our findings, van der Sluis et al. (2005) reported that when differences in general intelligence were considered, there were no significant differences in WM between children with DD (with or without arithmetic disability) and TR. This finding indicates that group differences in WM may be attributable to differences in general intelligence. Relationships between WM capacity and intellectual ability have also been documented by studies of typically 
developing children and young adults (Ackerman, Beier, \& Boyle, 2005; Cornoldi, Orsini, Cianci, Giofrè, \& Pezzuti, 2013).

Because a multivariate main effect of reading group was observed for both the PL and CE tasks, we examined whether differences in the PL might underlie the group differences in the CE. Indeed, after controlling for the PL tasks, the group differences in CE tasks were no longer significant, suggesting that the most relevant WM deficits in DD may be in PL functioning, rather than in the CE. Schuchardt et al. (2008) also observed that when the influence of PL was controlled for, the differences in measures of CE between dyslexic (with or without comorbid dyslexia/dyscalculia) and non-dyslexic children (TR and children with dyscalculia) were no longer significant.

Another purpose of the present study was to analyze the accuracy of WM measures in discriminating between children with DD and TR. There has been limited research utilizing ROC curve and binary logistic regression analyses to study WM deficits in DD. Shifting ability (Trail B-A) and the capacity to maintain (Forward DS) and manipulate (Backward DS) digits in memory revealed a moderate level of diagnostic accuracy. Binary logistic regression analyses also showed that these three tasks were reliable predictors of DD; the PL and CE tasks correctly predicted group membership for $68.7 \%$ and $65.6 \%$ of the children, respectively. These findings suggest that PL and CE tasks may be adequate measures to correctly discriminate between children with DD and TR in the Portuguese orthography. Obviously, the information obtained from WM measures should only be a component of the DD clinical diagnosis and need to be viewed in the context of a more comprehensive assessment. Similarly, in a recent crosslinguistic study involving six different languages (Finnish, Hungarian, German, Dutch, French, and English) spanning a large range of orthographic complexity, Landerl and colleagues (2013) found that verbal STM/CE was a significant predictor of DD status, independently of the level of orthographic complexity. All these findings highlight the need for future studies to include 
such statistical analyses; the presence of significant group differences alone does not imply that WM tasks can discriminate between subjects with sufficient accuracy.

The final purpose of the present study was to analyze the predictive effects of WM tasks on reading and spelling abilities. The relative contribution of each WM task to reading and spelling performance was evaluated using hierarchical linear regression analyses. As expected, the VSSP tasks were not significant predictors for any of the dependent variables under study. Conversely, the Verbal Learning Test (PL) and the Backward DS (CE) were significant predictors for all the reading and spelling measures. Concerning reading, the Backward DS was the most robust predictor for the three reading measures (particularly reading fluency, with $15.1 \%$ of unique variance), whereas the Forward DS (PL) contributed to only a small but significant proportion of the unique variance in reading fluency alone. In a sample of firstgraders, Nevo and Breznitz (2011) also found that the Backward DS task made the largest contribution to the explanation of unique variance in reading accuracy and in reading fluency, whereas the Forward DS task was a non-significant predictor. Similar to the VSSP tasks, the Trail B-A (CE) did not account for a significant degree of unique variance, suggesting that variance in reading is related to the storage and processing of verbal information rather than to shifting or visuospatial STM capacity. Thus, our findings are consistent with those of previous studies reporting links between WM (PL and CE components) and reading ability (Gathercole et al., 2006; Kibby, 2009; Swanson \& Ashbaker, 2000). Other studies of typically developing children (Ziegler et al., 2010) and children with DD (Boets et al., 2010) have found that the PL predicted reading ability even after controlling for other neurocognitive variables (phonological awareness and rapid naming) known to be strong predictors of reading.

Compared to reading, the number of studies exploring the relationship between WM and spelling is clearly limited (some exceptions: Service \& Turpeinen, 2001; Steinbrink \& Klatte, 2008). As Savage et al. (2007, p. 202) noted, this is surprising because "early spelling might 
thus be expected to tap central executive and phonological loop resources to a greater degree than in early word reading". The majority of studies analyzing the predictive value of WM measures for spelling ability have used samples of English-speaking children. For instance, Jongejan, Verhoeven, and Siegel (2007) found that verbal WM was a significant predictor of spelling and explained more unique variance in spelling than in reading. Similar to our reading results, we observed that only simple (Forward DS and Verbal Learning Test) and complex (Backward DS) verbal span tasks were significant predictors of spelling in our sample of Portuguese children. Furthermore, WM (particularly PL and CE tasks) explained more variance in spelling than in reading, suggesting that spelling is more dependent on WM resources than is reading accuracy, even in an orthography that is more transparent than English.

Notwithstanding the relevance of the present study described above, there were at least three limitations that should be addressed in future research. First, only two measures were used to assess each WM component. Certainly, the inclusion of more tasks per component would have increased the construct validity and the interpretability of the results. The inclusion of tasks tapping articulatory rehearsal (PL), static visual span (VSSP), and complex visuospatial span (CE) would be particularly relevant to better elucidate the presence of WM impairments in DD. Second, because there is a well-established, considerable overlap between the cognitive processes involved in $\mathrm{CE}$ and executive functions, it would be interesting to investigate the contribution of executive function tasks to the CE score differences between children with DD and TR. Third, because WM capacity is also significant impaired in ADHD (Kasper, Alderson, \& Hudec, 2012; Katz, Brown, Roth, \& Beers, 2011) and in dyscalculia (Landerl et al., 2009; Schuchardt et al., 2008), it would be particularly interesting to compare WM performance between children with DD and children with those two neurodevelopmental disorders.

\section{References}


Ackerman, P. L., Beier, M. E., \& Boyle, M. O. (2005). Working memory and intelligence: The same or different constructs? Psychological Bulletin, 131(1), 30-60. doi: 10.1037/00332909.131.1.30

Andersson, U. (2008). Working memory as a predictor of written arithmetical skills in children: The importance of central executive functions. British Journal of Educational Psychology, 78(2), 181-203. doi: 10.1348/000709907x209854

Ashkenazi, S., Rosenberg-Lee, M., Metcalfe, A. W. S., Swigart, A. G., \& Menon, V. (2013). Visual-spatial working memory is an important source of domain-general vulnerability in the development of arithmetic cognition. Neuropsychologia, 51(11), 2305-2317. doi: 10.1016/j.neuropsychologia.2013.06.031

Bacon, A. M., Parmentier, F. B. R., \& Barr, P. (2013). Visuospatial memory in dyslexia: Evidence for strategic deficits. Memory, 21(2), 189-209. doi: $10.1080 / 09658211.2012 .718789$

Baddeley, A. D. (1996). Exploring the central executive. The Quarterly Journal of Experimental Psychology, 49A(1), 5-28. doi: 10.1080/713755608

Baddeley, A. D. (2000). The episodic buffer: A new component of working memory? Trends in Cognitive Sciences, 4(11), 417-423. doi: 10.1016/S1364-6613(00)01538-2

Baddeley, A. D. (2002). Is working memory still working? European Psychologist, 7(2), 85-97. doi: $10.1027 / / 1016-9040.7 .2 .85$

Baddeley, A. D. (2003). Working memory: Looking back and looking forward. Neuroscience, 4(10), 829-839. doi: 10.1038/nrn1201

Baddeley, A. D. (2012). Working memory: Theories, models, and controversies. Annual Review of Psychology, 63(1), 1-29. doi: 10.1146/annurev-psych-120710-100422

Baddeley, A. D. (2013). Working memory and emotion: Ruminations on a theory of depression. Review of General Psychology, 17(1), 20-27. doi: 10.1037/a0030029 
Baddeley, A. D., Allen, R. J., \& Hitch, G. J. (2011). Binding in visual working memory: The role of the episodic buffer. Neuropsychologia, 49(6), 1393-1400. doi: 10.1016/j.neuropsychologia.2010.12.042

Baddeley, A. D., Banse, R., Huang, Y.-M., \& Page, M. (2012). Working memory and emotion: Detecting the hedonic detector. Journal of Cognitive Psychology, 24(1), 6-16. doi: $10.1080 / 20445911.2011 .613820$

Baddeley, A. D., \& Hitch, G. J. (1974). Working memory. In G. A. Bower (Ed.), The psychology of learning and motivation (pp. 47-89). New York: Academic Press.

Berninger, V. W., Abbott, R. D., Thomson, J., Wagner, R., Swanson, H. L., Wijsman, E. M., \& Raskind, W. (2006). Modeling phonological core deficits within a working memory architecture in children and adults with developmental dyslexia. Scientific Studies of Reading, 10(2), 165-198. doi: 10.1207/s1532799xssr1002_3

Boets, B., de Smedt, B., Cleuren, L., Vandewalle, E., Wouters, J., \& Ghesquière, P. (2010). Towards a further characterization of phonological and literacy problems in Dutchspeaking children with dyslexia. British Journal of Developmental Psychology, 28(1), 531. doi: $10.1348 / 026151010 \times 485223$

Bora, E., Vahip, S., Akdeniz, F., İlerisoy, H., Aldemir, E., \& Alkan, M. (2008). Executive and verbal working memory dysfunction in first-degree relatives of patients with bipolar disorder. Psychiatry Research, 161(3), 318-324. doi: 10.1016/j.psychres.2007.09.002

Brunswick, N., Martin, G. N., \& Marzano, L. (2010). Visuospatial superiority in developmental dyslexia: Myth or reality? Learning and Individual Differences, 20(5), 421-426. doi: 10.1016/j.lindif.2010.04.007

Caplan, D. (1992). Language: Structure, processing, and disorders. Cambridge, MA: The MIT Press. 
Carvalho, A., \& Pereira, M. (2009). O Rei - Um teste para avaliação da fluência e precisão da leitura no $1^{\circ}$ e $2^{\circ}$ ciclos do Ensino Básico [The King - Assessment test of the reading fluency and precision in the first and second cycles of elementary school]. Psychologica, 51, 283-305.

Clercq-Quaegebeur, M., Casalis, S., Lemaitre, M., Bourgois, B., Getto, M., \& Vallée, L. (2010). Neuropsychological profile on the WISC-IV of French children with dyslexia. Journal of Learning Disabilities, 43(6), 563-574. doi: 10.1177/0022219410375000

Cornoldi, C., Orsini, A., Cianci, L., Giofrè, D., \& Pezzuti, L. (2013). Intelligence and working memory control: Evidence from the WISC-IV administration to Italian children. Learning and Individual Differences, 26, 9-14. doi: 10.1016/j.lindif.2013.04.005

Cowan, N. (1999). An embedded-processes model of working memory. In A. Miyake \& P. Shah (Eds.), Models of working memory: Mechanisms of active maintenance and executive control (pp. 62-101). Cambridge, UK: Cambridge University Press.

de Jong, P. F. (1998). Working memory deficits of reading disabled children. Journal of Experimental Child Psychology, 70(2), 75-96. doi: 10.1006/jecp.1998.2451

Della Sala, S., Gray, C., Baddeley, A., Allamano, N., \& Wilson, L. (1999). Pattern span: A tool for unwelding visuo-spatial memory. Neuropsychologia, 37(10), 1189-1199. doi: $10.1016 / \mathrm{S} 0028-3932(98) 00159-6$

Drane, D. L., Yuspeh, R. L., Huthwaite, J. S., \& Klingler, L. K. (2002). Demographic characteristics and normative observations for derived-trail making test indices. Neuropsychiatry, Neuropsychology, and Behavioral Neurology, 15(1), 39-43.

Engle, R. W., Kane, M. J., \& Tuholski, S. W. (1999). Individual differences in working memory capacity and what they tell us about controlled attention, general fluid intelligence, and functions of the prefrontal cortex. In A. Miyake \& P. Shah (Eds.), Models of working 
memory: Mechanisms of active maintenance and executive control (pp. 102-134). Cambridge, UK: Cambridge University Press.

Fawcett, T. (2006). An introduction to ROC analysis. Pattern Recognition Letters, 27(8), 861874. doi: 10.1016/j.patrec.2005.10.010

Festas, I., Martins, C., \& Leitão, J. (2007). Avaliação da compreensão escrita e da leitura de palavras na PAL-PORT [Assessment of reading comprehension and word reading in PAL-PORT]. Revista Educação: Temas e Problemas, 4(2), 223-239.

Gathercole, S. E., Alloway, T. P., Willis, C., \& Adams, A.-M. (2006). Working memory in children with reading disabilities. Journal of Experimental Child Psychology, 93(3), 265-281. doi: 10.1016/j.jecp.2005.08.003

Goff, D., Pratt, C., \& Ong, B. (2005). The relations between children's reading comprehension, working memory, language skills and components of reading decoding in a normal sample. Reading and Writing, 18(7-9), 583-616. doi: 10.1007/s11145-004-7109-0

Helland, T., \& Asbjornsen, A. (2004). Digit span in dyslexia: Variations according to language comprehension and mathematics kills. Journal of Clinical and Experimental Neuropsychology, 26(1), 31-42. doi: 10.1076/jcen.26.1.31.23935

Holmes, J., Adams, J. W., \& Hamilton, C. J. (2008). The relationship between visuospatial sketchpad capacity and children's mathematical skills. European Journal of Cognitive Psychology, 20(2), 272-289. doi: 10.1080/09541440701612702

Hulme, C., Goetz, K., Gooch, D., Adams, J., \& Snowling, M. J. (2007). Paired-associate learning, phoneme awareness, and learning to read. Journal of Experimental Child Psychology, 96(2), 150-166. doi: 10.1016/j.jecp.2006.09.002

Jeffries, S., \& Everatt, J. (2004). Working memory: Its role in dyslexia and other specific learning difficulties. Dyslexia, 10(3), 196-214. doi: 10.1002/dys.278 
Jerman, O., Reynolds, C., \& Swanson, H. L. (2012). Does growth in working memory span or executive processes predict growth in reading and math in children with reading disabilities? Learning Disability Quarterly, 35(3), 144-157. doi: $10.1177 / 0731948712444276$

Jongejan, W., Verhoeven, L., \& Siegel, L. S. (2007). Predictors of reading and spelling abilities in first- and second-language learners. Journal of Educational Psychology, 99(4), 835851. doi: 10.1037/0022-0663.99.4.835

Just, M. A., \& Carpenter, P. A. (1992). A capacity theory of comprehension: Individual differences in working memory. Psychological Review, 99(1), 122-149. doi: 10.1037/0033-295X.99.1.122

Kane, M. J., Hambrick, D. Z., Tuholski, S. W., Wilhelm, O., Payne, T. W., \& Engle, R. W. (2004). The generality of working memory capacity: A latent-variable approach to verbal and visuospatial memory span and reasoning. Journal of Experimental Psychology: General, 133(2), 189-217. doi: 10.1037/0096-3445.133.2.189

Kasper, L. J., Alderson, R. M., \& Hudec, K. L. (2012). Moderators of working memory deficits in children with attention-deficit/hyperactivity disorder (ADHD): A meta-analytic review. Clinical Psychology Review, 32(7), 605-617. doi: 10.1016/j.cpr.2012.07.001

Katz, L. J., Brown, F. C., Roth, R. M., \& Beers, S. R. (2011). Processing speed and working memory performance in those with both ADHD and a reading disorder compared with those with ADHD alone. Archives of Clinical Neuropsychology, 26(5), 425-433. doi: 10.1093/arclin/acr026

Kibby, M. Y. (2009). There are multiple contributors to the verbal short-term memory deficit in children with developmental reading disabilities. Child Neuropsychology, 15(5), 485506. doi: 10.1080/09297040902748218 
Kibby, M. Y., \& Cohen, M. J. (2008). Memory functioning in children with reading disabilities and/or attention deficit/hyperactivity disorder: A clinical investigation of their working memory and long-term memory functioning. Child Neuropsychology, 14(6), 525-546. doi: $10.1080 / 09297040701821752$

Kramer, J. H., Knee, K., \& Delis, D. C. (2000). Verbal memory impairments in dyslexia. Archives of Clinical Neuropsychology, 15(1), 83-93. doi: 10.1093/arclin/15.1.83

Landerl, K., Fussenegger, B., Moll, K., \& Willburger, E. (2009). Dyslexia and dyscalculia: Two learning disorders with different cognitive profiles. Journal of Experimental Child Psychology, 103(3), 309-324. doi: 10.1016/j.jecp.2009.03.006

Landerl, K., Ramus, F., Moll, K., Lyytinen, H., Leppänen, P. H. T., Lohvansuu, K., . . SchulteKörne, G. (2013). Predictors of developmental dyslexia in European orthographies with varying complexity. Journal of Child Psychology and Psychiatry, 54(6), 686-694. doi: $10.1111 /$ jcpp. 12029

Logie, R. H. (1995). Visuo-spatial working memory. Hove, UK: Lawrence Erlbaum Associates.

Logie, R. H., \& Pearson, D. G. (1997). The inner eye and the inner scribe of visuo-spatial working memory: Evidence from developmental fractionation. European Journal of Cognitive Psychology, 9(3), 241-257. doi: 10.1080/713752559

Maehler, C., \& Schuchardt, K. (2011). Working memory in children with learning disabilities: Rethinking the criterion of discrepancy. International Journal of Disability, Development and Education, 58(1), 5-17. doi: 10.1080/1034912x.2011.547335

McDougall, S., \& Donohoe, R. (2002). Reading ability and memory span: Long-term memory contributions to span for good and poor readers. Reading and Writing, 15(3-4), 359-387. doi: $10.1023 / \mathrm{a}: 1015224830778$ 
McLean, J. F., \& Hitch, G. J. (1999). Working memory impairments in children with specific arithmetic learning difficulties. Journal of Experimental Child Psychology, 74(3), 240260. doi: 10.1006/jecp.1999.2516

Menghini, D., Finzi, A., Carlesimo, G. A., \& Vicari, S. (2011). Working memory impairment in children with developmental dyslexia: Is it just a phonological deficity? Developmental Neuropsychology, 36(2), 199-213. doi: 10.1080/87565641.2010.549868

Meyers, J., \& Meyers, K. (1995). Rey Complex Figure and recognition trial. Odessa, FL: Psychological Assessment Resources.

Moura, O., Simões, M. R., \& Pereira, M. (2013). WISC-III Cognitive Profiles in Children with Developmental Dyslexia: Specific Cognitive Disability and Diagnostic Utility. Dyslexia. doi: $10.1002 /$ dys. 1468

Nevo, E., \& Breznitz, Z. (2011). Assessment of working memory components at 6 years of age as predictors of reading achievements a year later. Journal of Experimental Child Psychology, 109(1), 73-90. doi: 10.1016/j.jecp.2010.09.010

Parrila, R., Kirby, J. R., \& McQuarrie, L. (2004). Articulation rate, naming speed, verbal shortterm memory, and phonological awareness: Longitudinal predictors of early reading development? Scientific Studies of Reading, 8(1), 3-26. doi:

$10.1207 / \mathrm{s} 1532799 x$ ssr0801_2

Perez, T. M., Majerus, S., \& Poncelet, M. (2012). The contribution of short-term memory for serial order to early reading acquisition: Evidence from a longitudinal study. Journal of Experimental Child Psychology, 111(4), 708-723. doi: 10.1016/j.jecp.2011.11.007

Pickering, S. J. (2004). Verbal memory in the learning of literacy. In M. Turner \& J. Rack (Eds.), The study of dyslexia (pp. 131-156). New York: Kluwer Academic Publishers.

Pickering, S. J., Gathercole, S. E., Hall, M., \& Lloyd, S. A. (2001). Development of memory for pattern and path: Further evidence for the fractionation of visuo-spatial memory. The 
Quarterly Journal of Experimental Psychology, 54-A(2), 397-420. doi:

$10.1080 / 713755973$

Sarver, D. E., Rapport, M. D., Kofler, M. J., Scanlan, S. W., Raiker, J. S., Altro, T. A., \& Bolden, J. (2012). Attention problems, phonological short-term memory, and visuospatial short-term memory: Differential effects on near- and long-term scholastic achievement. Learning and Individual Differences, 22(1), 8-19. doi: 10.1016/j.lindif.2011.09.010

Savage, R., Lavers, N., \& Pillay, V. (2007). Working memory and reading difficulties: What we know and what we don't know about the relationship. Educational Psychology Review, 19(2), 185-221. doi: 10.1007/s10648-006-9024-1

Schuchardt, K., Maehler, C., \& Hasselhorn, M. (2008). Working memory deficits in children with specific learning disorders. Journal of Learning Disabilities, 41(6), 514-523. doi: $10.1177 / 0022219408317856$

Service, E., \& Turpeinen, R. (2001). Working memory in spelling: Evidence from backward typing. Memory, 9(4-6), 395-421. doi: 10.1080/09658210143000137

Sesma, H. W., Mahone, E. M., Levine, T., Eason, S. H., \& Cutting, L. E. (2009). The contribution of executive skills to reading comprehension. Child Neuropsychology, 15(3), 232-246. doi: 10.1080/09297040802220029

Seymour, P. H. K., Aro, M., \& Erskine, J. M. (2003). Foundation literacy acquisition in European orthographies. British Journal of Psychology, 94(2), 143-174. doi: $10.1348 / 000712603321661859$

Simões, M. R., Albuquerque, C. P., Pinho, M. S., Pereira, M., Seabra-Santos, M. J., Alberto, I., . .. Lopes, A. F. (in press). Bateria de Avaliação Neuropsicológica de Coimbra (BANC) [Coimbra Neuropsychological Assessment Battery]. Lisboa: Cegoc. 
Smith-Spark, J. H., \& Fisk, J. E. (2007). Working memory functioning in developmental dyslexia. Memory, 15(1), 34-56. doi: 10.1080/09658210601043384

Steinbrink, C., \& Klatte, M. (2008). Phonological working memory in German children with poor reading and spelling abilities. Dyslexia, 14(4), 271-290. doi: 10.1002/dys.357

Sucena, A., Castro, S. L., \& Seymour, P. (2009). Developmental dyslexia in an orthography of intermediate depth: The case of European Portuguese. Reading and Writing, 22(7), 791810. doi: $10.1007 / \mathrm{s} 11145-008-9156-4$

Swanson, H. L. (2011). Dynamic testing, working memory, and reading comprehension growth in children with reading disabilities. Journal of Learning Disabilities, 44(4), 358-371. doi: $10.1177 / 0022219411407866$

Swanson, H. L. (2012). Cognitive profile of adolescents with math disabilities: Are the profiles different from those with reading disabilities? Child Neuropsychology, 18(2), 125-143. doi: $10.1080 / 09297049.2011 .589377$

Swanson, H. L., \& Ashbaker, M. H. (2000). Working memory, short-term memory, speech rate, word recognition and reading comprehension in learning disabled readers: Does the executive system have a role? Intelligence, 28(1), 1-30. doi: 10.1016/S01602896(99)00025-2

Swanson, H. L., \& Jerman, O. (2007). The influence of working memory on reading growth in subgroups of children with reading disabilities. Journal of Experimental Child Psychology, 96(4), 249-283. doi: 10.1016/j.jecp.2006.12.004

Swanson, H. L., Zheng, X., \& Jerman, O. (2009). Working memory, short-term memory, and reading disabilities: A selective meta-analysis of the literature. Journal of Learning Disabilities, 42(3), 260-287. doi: 10.1177/0022219409331958

Swets, J. A. (1988). Measuring the accuracy of diagnostic systems. Science, 240(4857), 12851293. doi: $10.1126 /$ science. 3287615 
Tiffin-Richards, M. C., Hasselhorn, M., Woerner, W., Rothenberger, A., \& Banaschewski, T. (2008). Phonological short-term memory and central executive processing in attentiondeficit/hyperactivity disorder with/without dyslexia - evidence of cognitive overlap. Journal of Neural Transmission, 115(2), 227-234. doi: 10.1007/s00702-007-0816-3

van der Sluis, S., van der Leij, A., \& de Jong, P. F. (2005). Working memory in dutch children with reading- and arithmetic-related LD. Journal of Learning Disabilities, 38(3), 207221. doi: $10.1177 / 00222194050380030301$

Wechsler, D. (2003). Wechsler Intelligence Scale for Children (WISC-III) - Portuguese Version (M. R. Simões, A. M. Rocha, and C. Ferreira). Lisbon: Cegoc.

Willcutt, E. G., Pennington, B. F., Olson, R. K., Chhabildas, N., \& Hulslander, J. (2005). Neuropsychological analyses of comorbidity between reading disability and attention deficit hyperactivity disorder: In search of the common deficit. Developmental Neuropsychology, 27(1), 35-78.doi: 10.1207/s15326942dn2701_3

Wisniewski, I., Wendling, A.-S., Manning, L., \& Steinhoff, B. J. (2012). Visuo-spatial memory tests in right temporal lobe epilepsy foci: Clinical validity. Epilepsy \& Behavior, 23(3), 254-260. doi: 10.1016/j.yebeh.2011.12.006

Ziegler, J. C., Bertrand, D., Tóth, D., Csépe, V., Reis, A., Faísca, L., . . Blomert, L. (2010). Orthographic depth and its impact on universal predictors of reading: A cross-language investigation. Psychological Science, 21(4), 551-559. doi: 10.1177/0956797610363406 
Table 1

Means, Standard Deviations and Multivariate Analyses of Variance and Covariance

\begin{tabular}{|c|c|c|c|c|c|c|c|c|}
\hline & \multirow{2}{*}{$\begin{array}{l}\text { Readers } \\
M \pm S D\end{array}$} & \multirow{2}{*}{$\begin{array}{l}\text { with DD } \\
M \pm S D\end{array}$} & \multicolumn{3}{|c|}{ MANOVA } & \multicolumn{3}{|c|}{ MANCOVA (FSIQ) } \\
\hline & & & $F(1,98)$ & $p$ & $\eta_{p}^{2}$ & $F(1,97)$ & $p$ & $\eta_{p}^{2}$ \\
\hline \multicolumn{9}{|l|}{ Phonological Loop } \\
\hline Forward DS & $7.36 \pm 1.45$ & $6.20 \pm 1.13$ & 19.383 & $<.001$ & .167 & 12.101 & .001 & .112 \\
\hline Verbal Learning Test & $6.58 \pm 1.75$ & $5.59 \pm 1.60$ & 8.554 & .004 & .081 & 5.629 & .020 & .055 \\
\hline \multicolumn{9}{|l|}{ Visuospatial Sketchpad } \\
\hline Corsi Block Test & $7.74 \pm 1.93$ & $7.18 \pm 1.53$ & 2.570 & .112 & .026 & 1.119 & .293 & .012 \\
\hline Rey Complex Figure & $15.86 \pm 5.77$ & $15.25 \pm 5.67$ & 0.284 & .595 & .003 & 0.001 & .996 & .000 \\
\hline \multicolumn{9}{|l|}{ Central Executive } \\
\hline Backward DS & $4.56 \pm 1.34$ & $3.63 \pm 0.97$ & 15.439 & $<.001$ & .137 & 6.287 & .014 & .061 \\
\hline Trail B-A & $53.98 \pm 27.71$ & $77.00 \pm 36.11$ & 12.689 & .001 & .116 & 8.192 & .005 & .079 \\
\hline
\end{tabular}

Note: FSIQ = Wechsler Intelligence Scale for Children (Third Edition) Full Scale IQ, DS = Digit Span subtest of the

Wechsler Intelligence Scale for Children (Third Edition), DD = developmental dyslexia. 
Table 2

Receiver Operating Characteristics (ROC) Curve Analysis

AUC $(95 \% \mathrm{CI}) \quad S E \quad p$

Phonological Loop

$\begin{array}{llll}\text { Forward DS } & .737(.639-.835) & .050 & <.001 \\ \text { Verbal Learning Test } & .657(.550-.763) & .054 & .007\end{array}$

Visuospatial Sketchpad

Corsi Block Test

Rey Complex Figure

Central Executive

$$
.581(.468-.694)
$$$$
.530(.415-.646)
$$$$
.704(.602-.806)
$$$$
.707(.604-.810)
$$
$.707(.604-.810)$
.058

.059 .602

Backward DS

Trail B-A
.052

.052
$<.001$

$<.001$

Note: DS = Digit Span subtest of the Wechsler Intelligence Scale for Children (Third Edition), AUC = area under the curve, $\mathrm{CI}=$ confidence interval, $S E=$ standard error. 
Table 3

Binary Logistic Regression Analysis

\begin{tabular}{|c|c|c|c|c|c|}
\hline & Sensitivity (\%) & Specificity (\%) & $\beta$ & Wald's $\chi^{2}$ & Odds Ratio $(95 \% \mathrm{CI})$ \\
\hline Phonological Loop & 73.5 & 64.0 & & & \\
\hline Forward DS & & & -.709 & $10.570 * *$ & $0.492(0.321-0.755)$ \\
\hline Verbal Learning Test & & & -.257 & 3.494 & $0.773(0.590-1.013)$ \\
\hline Visuospatial Sketchpad & 62.0 & 48.0 & & & \\
\hline Corsi Block Test & & & -.182 & 2.373 & $0.833(0.661-1.051)$ \\
\hline Rey Complex Figure & & & -.014 & 0.151 & $0.986(0.919-1.058)$ \\
\hline Central Executive & 57.1 & 74.0 & & & \\
\hline Backward DS & & & -.670 & $7.475 * *$ & $0.512(0.317-0.827)$ \\
\hline Trail B-A & & & .019 & $5.641 *$ & $1.019(1.003-1.035)$ \\
\hline
\end{tabular}

Note: DS = Digit Span subtest of the Wechsler Intelligence Scale for Children (Third Edition), CI = confidence interval, ${ }^{*} p<.05, * * p<.01, * * * p<.001$ 
Table 4

Hierarchical Linear Regression Analysis

\begin{tabular}{|c|c|c|c|c|c|c|c|c|}
\hline Dependent Variable & Block & Predictors & $\Delta R^{2}$ & $B$ & $S E$ & $\beta$ & $t$ & $p r^{2}$ \\
\hline \multirow[t]{6}{*}{ Text Reading Accuracy } & 1 & Forward DS (PL) & .172 & 0.403 & 0.593 & .080 & 0.680 & .004 \\
\hline & & Verbal Learning Test (PL) & & 0.970 & 0.387 & .236 & $2.509^{*}$ & .051 \\
\hline & 2 & Corsi Block Test (VSSP) & .011 & -0.077 & 0.387 & -.019 & -0.200 & $<.001$ \\
\hline & & Rey Complex Figure (VSSP) & & 0.061 & 0.117 & .049 & 0.524 & .002 \\
\hline & 3 & Backward DS (CE) & .076 & 1.835 & 0.610 & .322 & $3.011 * *$ & .073 \\
\hline & & Trail B-A (CE) & & -0.010 & 0.022 & -.046 & -0.429 & .001 \\
\hline \multirow[t]{6}{*}{ Text Reading Fluency } & 1 & Forward DS (PL) & .338 & 4.243 & 2.043 & .200 & $2.077^{*}$ & .023 \\
\hline & & Verbal Learning Test (PL) & & 4.386 & 1.333 & .254 & $3.290 * *$ & .059 \\
\hline & 2 & Corsi Block Test (VSSP) & .012 & 2.188 & 1.335 & .127 & 1.638 & .015 \\
\hline & & Rey Complex Figure (VSSP) & & -0.148 & 0.403 & -.028 & -0.366 & .001 \\
\hline & 3 & Backward DS (CE) & .152 & 11.105 & 2.102 & .463 & $5.284 * * *$ & .151 \\
\hline & & Trail B-A (CE) & & 0.057 & 0.077 & .065 & 0.742 & .003 \\
\hline \multirow[t]{6}{*}{ Word Reading Accuracy } & 1 & Forward DS (PL) & .231 & 0.902 & 0.549 & .189 & 1.642 & .021 \\
\hline & & Verbal Learning Test (PL) & & 0.899 & 0.359 & .230 & $2.508^{*}$ & .048 \\
\hline & 2 & Corsi Block Test (VSSP) & .006 & 0.010 & 0.359 & .003 & 0.027 & $<.001$ \\
\hline & & Rey Complex Figure (VSSP) & & 0.032 & 0.109 & .027 & 0.295 & .001 \\
\hline & 3 & Backward DS (CE) & .057 & 1.510 & 0.565 & .279 & $2.672 * *$ & .055 \\
\hline & & Trail B-A (CE) & & -0.007 & 0.021 & -.037 & -0.357 & .001 \\
\hline \multirow[t]{6}{*}{ Word Spelling Accuracy } & 1 & Forward DS (PL) & .303 & 1.386 & 0.593 & .254 & $2.338^{*}$ & .038 \\
\hline & & Verbal Learning Test (PL) & & 1.071 & 0.387 & .241 & $2.768 * *$ & .053 \\
\hline & 2 & Corsi Block Test (VSSP) & .018 & 0.112 & 0.387 & .025 & 0.289 & .001 \\
\hline & & Rey Complex Figure (VSSP) & & 0.116 & 0.117 & .086 & 0.990 & .007 \\
\hline & 3 & Backward DS (CE) & .045 & 1.466 & 0.610 & .238 & $2.404 *$ & .040 \\
\hline & & Trail B-A (CE) & & -0.015 & 0.022 & -.066 & -0.671 & .003 \\
\hline
\end{tabular}

Note: ${ }^{*} p<.05,{ }^{* *} p<.01,{ }^{* * *} p<.001 ; B, S E, \beta$ and $t$ values are relative to the last block; $p r^{2}$ represents the unique variance of each predictor; DS = Digit Span subtest of the Wechsler Intelligence Scale for Children (Third Edition); PL = phonological loop; VSSP = visuospatial sketchpad; CE = central executive. 